\title{
A História da Loucura
}

\author{
Ana Verônica de Alencar ${ }^{1}$; Solange Gonçalves Rolim ${ }^{2}$; Pollyanna Nayara Belém Leite ${ }^{3}$
}

Resumo: O conceito de Saúde Mental é relativamente novo, introduzido nos Estados Unidos após a Segunda Guerra Mundial. Consistia na idéia de que era plausível intervir preventivamente nas questões relacionadas à doença mental. O presente artigo discorre sobre a história da loucura, à partir de consulta bibliográfica a autores consagrados e a artigos sobre a temática em questão. O objetivo é um resgate histórico de como se chegou ao conceito atual de doença mental, em oposição ao antigo termo, ainda muito utilizado, denominado loucura.

Palavras Chaves: Saúde mental, Loucura, História

\section{A History od Madness}

Abstract: The concept of mental health is relatively new, introduced in the United States after World War II. Consisted in the idea that it was plausible to intervene proactively on issues related to mental illness. This article discusses the history of madness, from the bibliographic acclaimed authors and articles on the subject in question. The goal is a historical review of how it came to the current concept of mental illness, in opposition to the old term, still often used, called madness.

Keyworlds: Mental health, Madness, History

\section{Introdução}

Lidar com uma série de comportamentos inusitados faz parte das atividades que, embora não explicitadas oficialmente, norteiam todas as ações e comportamentos dos profissionais da saúde, enquanto requisito para desempenhar seu papel e ser socialmente aceito, principalmente no tocante ao atendimento ao doente mental (MIRANDA e FUREGATO, 2001).

Cientificamente doença mental pode ser entendida como uma variação mórbida do normal, variação esta capaz de produzir prejuízo na performance global da pessoa (social, ocupacional, familiar e pessoal) e/ou das pessoas com quem convive (BALLONE, 2006).

\footnotetext{
${ }^{1}$ Ana Verônica de Alencar. Psicólogia pela Universidade Estadual da Paraíba (UEPB). Professora da Faculdade Kurios - Núcleo de PósGraduação, Pesquisa e Extensão , Brasil

${ }^{2}$ Solange Gonçalves Rolim é Psicóloga pela Universidade Federal da Paraíba, atuando nas áreas Clínica e Organizacional. E-mail: solangegrolim@ig.com.br;

${ }_{3}^{3}$ Pollyanna Nayara Belem Leite é Enfermeira e Pós-graduanda em Políticas Públicas em Saúde Coletiva pela Universidade Regional do Cariri - URCA. E-mail: pollybelem@yahoo.com.b
} 
Por outro lado o senso comum, exibe uma tendência em julgar a sanidade da pessoa, através dos seus comportamentos, tem características, sua adequação às conveniências sócio-culturais, como por exemplo, a obediência aos familiares, o sucesso no sistema de produção, a postura sexual, etc. (BALLONE, 2006).

Ao tentarmos enunciar a saúde e a doença, devemos estar cientes de que tais concepções possuem características únicas, de acordo com o contexto cultural dos diferentes grupos que compõe a sociedade. Além disso, saúde e doença não são valores abstratos ou condições estáticas. A compreensão acerca de saúde depende da visão que se tem do ser humano e de sua relação com o ambiente, podendo ainda variar de sujeito pra sujeito (BRASIL, 1998 apud GONÇALVES, 2005). Diante disto Gonçalves (p.14), afirma que:

[...] o conceito de saúde não está apenas restrito aos aspectos biológicos, mas às condições culturais, individuais, políticas, sociais, econômicas, históricas, tornandose um conceito muito amplo e complexo. Assim, torna-se necessário ressignificar e reconceituar o que seja saúde, vê-la não apenas no campo científico, mas também como movimento ideológico em aberto.

Para Herzlich (1996 apud ALVES; EULÁLIO e BRITO, 2004), saúde e doença não são apenas episódios orgânicos, mas acontecimentos psicossociais, modos de equilíbrio e desequilíbrio do homem em seu ambiente. Por meio do estudo dos aspectos sociais da saúde e da doença percebem-se como a mudança de valores, normas e modelos culturais influenciam a imagem destes objetos sociais. Do mesmo modo, também Canguilhem (1982) nos assegura que o normal biológico se revela a partir de "infrações" às normas, isto é, através da doença. A doença seria concebida como uma violação ao que foi consensualmente aceito como norma.

Saúde Mental é um conceito relativamente novo, introduzido nos Estados Unidos após a Segunda Guerra Mundial. Consistia na idéia de que era plausível intervir preventivamente nos ensejos da doença mental, expandindo o desempenho da psiquiatria para a comunidade, uma vez que, até então, se preocupava exclusivamente com o tratamento e a cura dos doentes (AMARANTE, 2003).

\section{A visão ocidental}

Segundo Silveira e Braga (2002), a sociedade ocidental moderna, seja ela médica ou psicológicas, produz e naturaliza uma visão do sofrimento psíquico como objeto de intervenção da ciência. Nesse modelo, o sofrimento psíquico recebe o título de doença mental, com quadros 
nosológicos visivelmente demarcados. O objetivo final, ou seja, a cura, pode até ser conceituada de modos distintos, mas, invariavelmente, resiste à noção de readaptação a um mundo, no qual ele não está incluso ou ao qual se mostra alheio.

Essa visão de mundo arvora-se em ser verdadeira e que já foi absorvida a tal ponto que se corre até mesmo o risco do ridículo se apresentarmos os fatos sob outra ótica. Contudo, a história mostra que nem sempre foi assim: loucura, alienação, doença mental, transtorno mental, sofrimento psíquico, nem sempre pensados de maneira uniforme nem ao longo da história, nem no mesmo espaço temporal. Vale salientar que a forma como a experiência com a loucura vai sendo conceituada, influencia diretamente os espaços e as práticas destinadas a ela. Sendo assim, uma reflexão sobre a temática demonstra a trajetória da percepção da loucura desde a Grécia Antiga até os dias atuais, enfocando, principalmente, os períodos onde ocorreram mudanças significativas na forma de se perceber e operar diante dessa experiência.

Para Souza (1999, apud GONÇALVES 2005), a história da loucura é a história de uma prática e de um saber idealizado coletivamente, atrelados com os tempos, as culturas e a sociedade dos seres humanos. Para o autor,

Não há sobre a loucura, a luz de uma arqueologia do saber, a verdade, mas uma sucessão de discursos complementares e contraditórios, que rompem e reconstroem a cada momento do tempo um olhar diferente sobre a loucura. (p.50.).

Pelbart (1989) revê diferentes percepções sócio-históricas da loucura desde a antiguidade grega até as concepções modernas, começando por Sócrates e Platão analisando a variação histórica da loucura e, situando a questão da alienação como saúde e/ou doença.

Para Platão havia dois tipos de loucura: a loucura humana ligada às inquietações do espírito pelo desequilíbrio do corpo; e a loucura divina, que estaria associada a questões proféticas, poéticas e eróticas. No tocante às modalidades de loucura divina, a loucura grega se aproxima da razão gerando uma relação muito estreita entre sabedoria e delírio. Assim na visão antiga da loucura, a palavra delirante não era relegada ao "não-ser", isto é, não era desqualificada em relação ao razão e que loucura e pensamento nem sempre foram excludentes ou conflitantes, pois havia uma "dimensão de saber" na mania grega que representava uma outra forma de acesso à verdade divina. (PELBART, 1989, p. 40).

Assim para o autor, logos grego não tinha contrário. O delírio divino só podia ser pensado como um além da razão. Na antiguidade grega nem sempre o que intitulamos de loucura denotou, apenas, doença.

Já nos fins da Idade Média ao século XVI o conceito de loucura começa a divergir com o que se pensava na Grécia Antiga. Inicia-se nesse período a ruptura entre razão e desrazão. A desrazão criaria, de certa forma, a própria razão. 
Foucault (1961, apud PASSOS e BEATO, 2003) explicita melhor a concepção de loucura no período da Renascença, ele toma esta época histórica como berço da ruptura moderna do diálogo entre razão e loucura, e a conseqüente identificação desta última, como desrazão. Por sua vez a loucura não está completamente identificada com a perda da razão, como desrazão, nem como legítima negatividade. Ao contrário, a Loucura ao ser dessacralizada, vem a habitar o mundo humano, descobrindo um espaço faiscante na literatura e nas artes.

Na idade clássica para Foucault (1961, apud PASSOS e BEATO, 2003), ocorre uma mudança na visão crítica da loucura, adversa à razão, operando uma identificação do louco com outros tipos de desviantes sociais (vagabundos, delinqüentes, prostitutas e marginais de toda ordem). Esta visão, a serviço do saneamento das cidades, passa a ser cada vez mais predominante, fazendo praticamente dissipar a visão nefasta renascentista, e registrando a loucura no curso da desordem a ser abafada ou reprimida.

Entrando na modernidade pós-revolucionária, encontraremos o médico Philippe Pinel, e com ele o nascimento do modelo asilar de tratamento do louco. Segundo Jacobina (2003), o procedimento pineliano de tratamento da loucura se apoiava em fortalecer a autoridade moral do médico, retratado como um pedagogo firme, porém justo, que reorientaria a razão perdida do paciente. Marchewka (2001, apud JACOBINA, 2003) fala ainda que essas técnicas deveriam ser sobrepostas num ambiente controlado, longe das paixões corrompedoras e dissimuladas, produzidas pela civilização onde os 'sprits aliénés' regressaria ao seu estado 'natural'. Há, deste modo, certa analogia entre loucura e moral - já que o tratamento moral recomendado consistia exatamente em usar da rigidez científica e da insuspeição moral do médico para "convencer" o louco a retornar à sanidade mental.

Explicitam-se, pois, outros pressupostos que lastreiam a percepção moderna de loucura, especialmente no direito penal - a loucura como "inferioridade moral", estado do qual as pessoas poderiam ser "trazidas de volta" ao rumo da "sanidade" se separadas das forças alienadoras da sociedade - vale dizer, se perdessem a liberdade psicológica da loucura, e fossem guiados pela mão segura do alienista, não lhes restaria mais do que trilhar o caminho da normalidade. A cura, nessa compreensão, seria o regressar a um estado ilusório simbolizado pelo "homo medius" - o estado "normal" - por mais metafísica que o conhecimento de normalidade possa parecer. Ainda porque tanto a noção de homem médio quanto a noção de normalidade são apenas devaneios racionais. (JACOBINA, 2003)

Ainda segundo Foucault (1961, apud PASSOS e BEATO, 2003 p. 19) em relação ao modelo asilar afirma que:

[...] encontrou suas condições de possibilidade no "grande internamento" que teve lugar na Europa nos séculos XVII e XVIII. Internando-se os loucos em hospitais gerais, junto com todo tipo de indesejáveis sociais, o grande gesto do internamento 
foi produzindo uma mudança fundamental nas percepções anteriores da loucura (místicas, religiosas etc.) como desrazão, lançando as bases de um novo tipo de domínio - o silenciamento e a segregação do louco do convívio social. Esses hospitais gerais não tinham qualquer finalidade terapêutica, nem significação médica $[\ldots]$.

Com o aparecimento da psiquiatria em fins do século XVIII, ocorre a crítica do internamento generalizado, e delegando o asilo como lugar de confinamento e tratamento especialmente destinado aos loucos. O alienismo, como foi definido essa primeira psiquiatria, consolida-se nesse espaço asilar reformado, brotando uma nova concepção da loucura que se torna dominante, e inscrevendo-a no domínio médico como doença e inabilidade para o trabalho, ou impossibilidade de integração social (PASSOS e BEATO 2003).

Pelbart (1989) vê em Hegel filósofo contemporâneo, que enxerga a loucura mais como uma relação interior à razão (uma contradição na razão) do que uma ausência de razão, Pelbart percebe esta loucura fortemente ligada à linguagem, pois é na medida em que o sujeito fala e significa que um sentido do dito pode vir a trocar e desalojar a afetividade do ser. Ainda em Hegel, quanto mais incólume estiver à razão de um louco, maior será sua loucura, pois maior será o seu conflito. Pois a loucura não é desvairo do discurso, mas o alto conflito interior que gera essa insensatez sendo o sujeito àquele que suplanta esse conflito, fazendo da loucura uma fase fundamental do eu no seu processo de autonomia. Assim a ligação entre Hegel e o alienismo dá-se apenas na medida em que a loucura, passando a ser vista como fenda, subjetividade despedaçada e sofrida, pôde abrir-se para o comércio terapêutico, passando, portanto a ser curável.

Logo, entre a Antiguidade e a Modernidade teria sucedido um extenso deslizamento da loucura em direção a um novo lugar social (o asilo) e simbólico (a doença). E seguindo este deslizamento, estabelece com o louco uma nova relação: "Se é verdade que a antiguidade grega manteve com o louco uma proximidade de fato e uma distância absoluta de direito, (...) à época moderna a identidade com ele é direito e a distância é de fato" (PELBART, 1989, p. 46).

Assim a loucura tornada natural e interiorizada como experimento humano na modernidade, passa a instituir ao louco um novo e paradoxal lugar ou regulamento social: o direito ao cuidado, a um tratamento específico e particularizado, que o discrimina de outras formas de desviantes sociais (o criminoso, o vagabundo, o delinqüente etc.), mas que concebe, no mesmo gesto, a alienação de sua subjetividade e cidadania no saber e poder médico, onde muitas vezes com lesão do direito ao convívio social. (PASSOS e BEATO, 2003).

A história da loucura nos séculos XVIII e XIX é quase sinônimo da história de sua busca pelos conceitos de alienação e, mais tarde, de doença mental. Esse processo tem seu significado vinculado à criação de um novo modelo de homem ou de um novo sujeito na modernidade. Esse sujeito se funda no surgimento da idéia de indivíduo e se concretiza na consolidação do sujeito do conhecimento 
http://idonline.emnuvens.com.br/id

ISSN on-line: 1981-1179

cartesiano, pautado na racionalidade científica que se torna hegemônica como método de produção de conhecimento. Passando assim a existir um pensamento mecanicista, baseado nos princípios de causalidade e previsibilidade, esta racionalidade permite o surgimento de um sujeito da Razão. A loucura se torna seu contraponto: é capturada como sujeito da desrazão (TORRE e AMARANTE, 2001). Acerca disso, Torre e Amarante (2001, p.74) diz que:

Analisar a história da loucura remete a análise de como a modernidade se constitui como forma de pensamento e organização social e como ela forja uma forma de lidar com a loucura como fenômeno humano e social. Em outras palavras, uma análise da forma da produção de saberes e de exercício do poder sobre os sujeitos que constitui a modernidade.

Delgado (1998 apud GONÇALVES, 2005) analisa essa forma de produção de saberes e de exercício do poder através da medicina psiquiátrica, abalizando, ao longo da história, alguns marcos que orientaram a assistência ao doente mental. A nomeação de Pinel para direção de Bicêtre, (um hospital francês) em 1793, por exemplo, começou a se difundir uma concepção equivocada sobre a loucura, pois ele fundamentava a alienação mental como sendo um distúrbio das funções intelectuais do sistema nervoso, sustentando a idéia de que o cérebro é a sede da mente onde se revelava tal distúrbio. Além disso, outro marco foi à viabilização de psicofármacos como medida terapêutica, e a mais drástica solução - o isolamento ou a internação, separando o doente da sociedade e da família. Porém todos os recursos utilizados pela psiquiatria demonstraram falência, no sentido de que não ajudou o problema do doente mental.

Uma importante questão a respeito desse ponto do isolamento e confinação do doente mental é verificada na concepção da loucura no Brasil, onde nas últimas décadas passou por modificações, com avanços que vem se constituindo na prática institucional da saúde mental.

Segundo Fraga (1994), no Brasil, o período de 1852 a 1979, é reconhecido como cristalizador na exclusão do louco, fortalecendo assim sistematicamente, a hegemonia da medicina no interior dos hospícios que ao seu modo ajudou para a política expansionista da construção de mais asilos e colônias em várias regiões do país, reproduzindo a cronificação, a superlotação, e a elevada taxa de mortalidade da população asilar. Em 1940 nasce os ambulatórios psiquiátricos com o intento de diminuir as superlotações e assistir os doentes mentais de condições miseráveis de vida. Nas décadas posteriores, com aparecimento das drogas antipsicóticas o nível e a qualidade da assistência psiquiátrica não aliviaram a destinação social do doente mental, sempre elemento de exclusão e segregação, agregada aos maus tratos e favorecendo a sua cronificação. Na década de 70, por meio de convênios com instituições privadas, a assistência psiquiátrica é incorporada à previdência social firmando um dos maiores parques manicomiais do mundo. Essa época é conhecida como a indústria

Id en line Revista de Psicologia. Ano 7, No. 21, Novembroo/2013 - ISSN 1981-1179

Edição eletrônica em http://idonline.emnuvens.com.br/id 
http://idonline.emnuvens.com.br/id

ISSN on-line: 1981-1179

da loucura, caracterizada pela alta lucratividade, tratamento desumano no interior dos serviços, medicalização exagerada, maus tratos, segregação, cronificação e descompromisso com a vida.

Segundo (MIRANDA; ARDAIA; ARAÚJO, 2000) que tece alguns comentários sobre a assistência psiquiátrica no Brasil diz que: em meados dos anos 80, começa a emergir as denuncias dos profissionais da área de saúde, de alguns seguimentos sociais e, sobretudo, da mídia contra essa indústria, sendo, inclusive, responsabilizada pela falência do sistema previdenciário vigorante. Assim diante deste quadro, algumas táticas emergiram no sentido de resgatar a cidadania do doente mental, através de denúncias, fórum de discussões pela luta anti-manicomial sugerindo transformações na legislação psiquiátrica, sanitária e trabalhista tentando na medida do possível, transformar o quadro do doente mental no Brasil, bem como da loucura.

Assim como o tema da doença mental, a sexualidade aparece como peça fundamental para a construção social do sujeito moderno, tendo-se constituído a partir do século XVIII como um domínio separado, de um universo simbólico mais abrangente que continha fenômenos como: a sensibilidade e a sensualidade (DUARTE, 1999 apud VENANCIO, 2005).

Miranda e Furegato (2004) se referem ao preconceito manifesto sobre a sexualidade do doente mental como parte de um mascaramento social ou uma negação maior e espúria. A negação, repetida no contexto institucional e profissional, simula um fragmento da sociedade.

Os mesmos autores falam que a imagem corporal do doente mental, na conjuntura da instituição, pode ser descrita como um corpo despojado de beleza e de vigor físico confirmando assim, a negação de um sujeito sexualmente desejável e desejante. Sobre os aspectos físicos desses indivíduos advem o preconceito por não se reconhecer, no contexto institucional, o corpo jovem, funcional, útil e desejado.

Schilder (1980 apud MIRANDA e FUREGATO, 2004) se refere aos cuidados da enfermagem ao doente mental localizados no corpo do paciente e identifica por meio desses profissionais como a sexualidade do portador de doença mental é: negada, censurada, discriminada e estigmatizada, atuando aí a composição fisiológica e libidinal que formam a imagem corporal e sociológica deste indivíduo. Portanto,

[...] o cuidado de enfermagem, direcionado para o aspecto fisiopatológico, no sentido amplo da atuação profissional, está sempre alerta para os perigos dessa estrutura, afastando o profissional, quando confrontado com as zonas erógenas, especialmente a genitália. Preferencialmente, os cuidados "devem" estar a cargo de profissionais do mesmo sexo, o que não exclui a presença das manifestações libidinais. Essa situação real e presente (não dita e não ensinada) levam o profissional a adotar o afastamento e até a negação da mesma. A fragmentação corporal começa no ensino. É reforçada a estrutura fisiopatológica, com procedimentos técnicos sistematizados, de prevenção, promoção e manutenção da saúde, dentro do modelo organicista. Entretanto, há obscurecimento das outras estruturas que complementam a noção de imagem corporal, como se as mesmas se 
estruturassem em dimensões diferentes, ou seja, o ensino omite os aspectos libidinal, emocional e sociológico da conduta humana.

Sobre o corpo, a pressão para o estigma - a sexualidade como desvio O indivíduo é percebido a partir de certos atributos que o identificam socialmente. $\mathrm{O}$ estigma marca a pessoa, acusa, censura, condena. O estigma apresenta como característica uma evidência sobre o corpo do outro, que passa a ser considerado diferente, passível de reclassificação, podendo ser visto como um defeito, uma fraqueza ou uma desvantagem.

A negação da sexualidade do doente mental coaduna-se com a noção de desvio, por ser indicativo de estigma, visto que as deformidades físicas e os problemas relacionados ao caráter da pessoa dão sustentação a esse quadro (MIRANDA e FUREGATO, 2004, p.211)

Em resumo, atrelar Doença Mental e Sexualidade, parece evidenciar um conjunto de atitudes, por parte dos profissionais, que beneficia muito mais a repressão e negação da sexualidade no sujeito portador de doença mental, do que a sua vivência saudável.

Kempton (1983 apud BALLONE, 2006), discutindo as diferentes atitudes face à sexualidade das pessoas portadoras de doença mental, avalia que estas podem ser encaradas como eternas crianças, dignas de piedade, pelo que precisam ser tratadas com benevolência. Esta atitude, paternalista, avalia a sexualidade nas pessoas portadoras de deficiência mental como inexistente; se existe, apesar de tudo, há que negá-la e sublimá-la; uma outra atitude perante a esse indivíduos é que são considerados como seres Infra-humanos, como seres imperfeitos ou grosseiros, mais próximos dos instintos dos animais do que dos seres humanos e devem, por isso, permanecer reclusas. Quando acontecem comportamentos sexuais as reações são, na generalidade, de medo e de repulsa.

\section{Conclusão:}

Assim, o modelo de atuação do profissional, na visão tecnicista, estabelece os meios de atendimento do portador de doença mental, de forma a cumprir as determinações do poder hegemônico, com raras intervenções no sentido de uma assistência compreensiva ou, ainda, com enfoque humanista. O modelo ideal de paradigma é uma conquista a ser empreendida por cada um de nós. 
Referências:

ALVES, R. F.; EULÁLIO, M. C.; BRITO, S. M. O. Representações sociais, via de acesso ao pensamento social sobre a saúde-doença. In: FERNANDES, A.; CARVALHO, M. R.; SOBRINHO, M. D. (Orgs.). Representações sociais e saúde: construindo novos diálogos. Campina Grande: EDUEP, 2004.

AMARANTE, P. (Coord.). Saúde Mental, políticas e instituições: programa de educação à distância. Rio de Janeiro: FIOTEC/FIOCRUZ, EAD. v.2, 2003.

BALlONe, G. J. O que é Doença Mental? 2006. In. Psiqweb: Psiquiatria Geral Disponível em: http://gballone.sites.uol.com.br/voce/doen.html. Acesso em 07 nov. 2006

CANGUILHEM, G. O normal e o patológico. Rio de Janeiro: Forense Universitária, 1982.

FRAGA, M. N. O.; Construção da reforma psiquiátrica brasileira: questão sobre o modo de inserção da enfermagem. In: Congresso Brasileiro de Enfermagem, 45., 1994, Recife. Enfermagem na perspectiva de saúde com qualidade. Recife, 1994.

GONÇALVES, C. C. O grito das mulheres foi ouvido: A experiência do grupo de Saúde mental da Equipe Amarela do Bairro do Pedregal - Campina Grande, Pb. 2005. 118f. Dissertação (Mestrado em Saúde Coletiva) - Faculdade de Ciências Biológicas, Universidade Estadual da Paraíba, Campina Grande, 2005.

JACOBINA, P. V.; Saúde mental e direito: Um diálogo sobre reforma psiquiátrica e sistema penal. 2003. Disponível em: http://www.scielo.br/pdf/rlae/v10n2/10516.pdf. Acesso em 20 de out. 2006.

MIRANDA, F. A. N. e FUREgATO, A. R. F. Percepções da Sexualidade do Doente Mental pelo Enfermeiro. 2001. Disponível em: http://www.scielo.br/pdf/rlae/v10n2/10516.pdf. Acesso em $10 \mathrm{de}$ out. 2006.

Representações sociais da atuação do enfermeiro psiquiátrico no cotidiano, 2004. Disponível em: http://www.mackenzie.com.br/universidade/psico/publicacao/. Acesso em: 12 de Dez. 2006.

Id en line Revista de Psicologia. Ano 7, No. 21, Novembroo/2013 - ISSN 1981-1179

Edição eletrônica em http://idonline.emnuvens.com.br/id 
MIRANDA, F. A. N.; ARDAIA, A. R. e ARAÚJO, K. L.; Cotidiano da enfermagem psiquiátrica no hospital geral: perspectiva dos profissionais da saúde. 2000. Disponível em: http://www.scielo.br/pdf/rlae/v10n2/10516.pdf. Acesso em 11 de nov. 2006.

PASSOS, I. C. F.; BEATO, M. S. F. Concepções e práticas sociais em torno da loucura: alcance e atualidade da história da loucura de Foucault para investigações etnográficas. 2003 Disponível em: http://www.scielo.br/scielo.php?script=sci. Acesso em 28 de nov. 2006.

PELBART, P. P.; Da clausura do fora ao fora da clausura. Rio de Janeiro: Graal, 1989.

SILVEIRA, L. C. e BRAGA, V. A. B.; Acerca do conceito de loucura e seus reflexos na assistência de saúde. 2002. Disponível em: http://www.scielo.br/scielo.php?script=sci. Acesso em 20 de nov. 2006.

TORRE, E. H. G. e AMARANTE, P. Protagonismo e subjetividade; a construção coletiva no campo da saúde mental. 2001. Disponível em http://www.scielo.br/scielo.php?script=sci. Acesso em 03 de out. 2006.

VEnAnCiO, A. T A. Doença Mental, Raça e Sexualidade nas Teorias Psiquiátricas de Juliano Moreira. 2005. Disponível em: http://www.scielo.br/scielo. php?script=sci. Acesso em 28 set. 2006.

Como citar este artigo (Formato ISO):

ALENCAR, A.V. ROLIM, S.A.; LEITE, P.N.B. História da loucura. Id on Line Revista de Psicologia, Novembro de 2013, vol.1, n.21, p. 15-24. ISSN 1981-1189. 